\title{
Mathematical Modeling and Simulation of Modern Cars in the Role of Stability Analysis
}

\author{
R. Anbazhagan ${ }^{1 *}$, B. Satheesh ${ }^{2}$ and K. Gopalakrishnan ${ }^{3}$ \\ 'Professor, Department of Automobile Engineering, Bharath University, \\ Chennai-73; anbazhagan.auto@bharathuniv.ac.in \\ 2 Professor, Department of ECE, Bharath University, \\ Chennai-73; satheesh.mit@gmail.com \\ 3Professor, Department of ECE, Bharath University, Chennai-73; gopikrishna2804@gmail.com
}

\begin{abstract}
In India Automobiles provide a vital infrastructure for the growth of industry and agriculture. Human civilization has inevitably relied on substantial movement of passengers and goods in a speedy manner and the volume of this has gone up enormously with massive rise in population and economic activity. The demand of higher operating speeds, greater axle loads, better riding comfort and more running safety has attracted the attention of professional talents to give a serious thought to the problem of vehicle system dynamics and to devise ways and means to achieve the above requirements through effective methods. At present, the researchers are trying to develop mathematical and computer models, which not only provide a more exact simulation but enable studies to be carried out on stability or response, comfort and optimization of the design characteristics of various components of the vehicle system. Vehicle dynamics, stability deals with the study of vehicle in motion under the action of various forces. Any vehicle comprises of linear as well as angular movements along and about the three mutually perpendicular coordinate directions $\mathrm{x}, \mathrm{y}, \mathrm{z}$. The linear movements are longitudinal, lateral and vertical displacements and the angular movements are rolling, pitching and yawing respectively for $\mathrm{x}, \mathrm{y}, \mathrm{z}$ directions.
\end{abstract}

Keywords: Vehicle Stability, Linear Movements, Simulation, Optimization, Vehicle Dynamics.

\section{Introduction}

\subsection{Vehicle System and Associated Problems}

In a vehicle system, the suspension along with the tyres is an important component, since it is responsible for the transmission of loads, along with the tyre and road contact forces. When the vehicle moves on an irregular road, large amount of forces are transmitted from the road to the vehicle through the tyres.

These wheel contact forces play an important role in the lateral dynamic performance of the vehicle which includes the stability which is required for the safety. It is important that any mathematical model whose aim is to predict the lateral performance with respect to the tyre road contact forces. Under certain conditions the tyre and road contact forces causes instability in the vehicle system. The above demands, force the automotive industry to find a way so as to reduce the design effort as well as the design time as low as possible. Computer modeling is one of the promising solutions for the lateral stability analysis and the aim of the work is to:

- Develop a mathematical model for the vehicle system

- Analyzing the various parameters which influence the stability using a computer program

- Application of the analysis to study the stability parameters of the vehicle system

*Corresponding author:

R. Anbazhagan (anbazhagan.auto@bharathuniv.ac.in) 
There is always a need to develop a mathematical model to analyze the stability and this work initiated the development of a mathematical model for the various movements of the vehicle and to study the parameters which influence the stability. In a vehicle system, the tyre-road contact surface is one of the most important components having direct bearing on vehicle stability, riding comfort at a maximum possible speed.

Under the challenge of demanding loads, increasing traffic and high speed operations its technology is moving fast. In a vehicle, the whole weight is transmitted to the road through the suspension system and the tyres. The Motor vehicle is equipped with a multitude of electrical and electronic sub-systems also. These sub-systems serve to provide various purposes such as operating the electric windows, air-conditioning systems, etc. Above all these purposes, that the systems also have control over the safety features such as antilock braking system, drive dynamics control, etc.

The manufacturers are forced to bring new models to the market as quickly as possible. This needs a decrease in the design effort of the various sub-systems thereby reducing the time required to design a new model from conception to production.

\section{State of Art}

The study of vehicle dynamics is a difficult and complex exercise. Use of computer is generally made to carry out such a study. The activity consists of computer modeling and simulation. Simulation results are interpreted to predict the behavior of the real system. A number of classical works in available literature have discussed in detail the subject of modeling and simulation.

Vehicle Dynamics involves the study of dynamic behavior of a vehicle. It has been often stated that the primary forces by which a high speed motor vehicle controlled are developed at four patches at the tyre-road interface. Knowledge of these forces and moments generated by the tyres at the tyre-road interface is essential. Moreover, the performance of the vehicle and its response to the forces developed in the system requires more time to study how and why such forces are produced.

\section{Directional Stability}

Directional stability depends on the horizontal plane moments applied to the vehicle under various maneuvering conditions due to composite tyre forces typically result from steering and or braking. Under accident avoidance conditions these forces are influenced by load transfer. Steering causes normal load to be transferred from inside to the outside tyres which decreases the force generating capacity of the inner tyres and increases the generating capacity of the outer tyres.

If the front tyre saturates first the vehicle under steers and plows out. If the rear tyre saturates first the vehicle over steers and spins out. The lateral load transfer is influenced by the ratio of centre of gravity height to track width. The saturation of the front relative to the rear can be controlled by adjusting the relative load transfer between the two axles.

Braking causes load transfer from the rear axle to the front axle. Under hard braking conditions the rear axle is lightly loaded which greatly restricts the rear axle braking force capacity relative to the front axle. To avoid rear axle lock up under hard braking conditions non linear proportioning valves are used. The longitudinal load transfer depends upon the ratio of centre of gravity height to the wheel base. It is the main factor for setting optional brake proportion.

The brake proportioning depends on brake pad a frictional property which varies depending on the use factors and quality control of serviceable components. Combined cornering and braking produces the most severe handling conditions. Braking in a turn can lead to over steer and directional in stability. Figure 1.1 shows the direction of movement of a vehicle in a two dimensional representation.

\section{Rollover Stability}

Rollover requires elevating the centre of gravity over the road surface on one side of the vehicle. Rollover occurs under severe lateral maneuvering conditions give rise to sufficient tyre side force capability. During cornering the tyre side force and the centripetal force due to the lateral acceleration leads to roll moment, which is sufficient to rollover the vehicle. The peak lateral acceleration maneuvering capability for light passenger vehicle are found at the order of $0.8 \mathrm{~g}$ due to tyre characteristics and the track width ratio is greater than unity.

\section{Tyre-Road Contact Forces of a Car}

The vertical force applied to the road surface by each tyre of a vehicle can be separated into two components, the 
SIDE VIEW

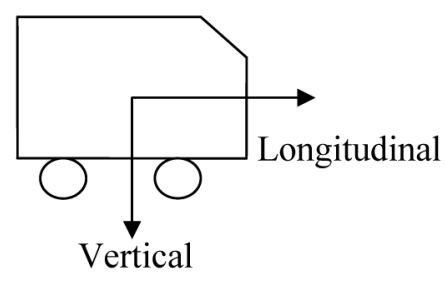

TOP VIEW

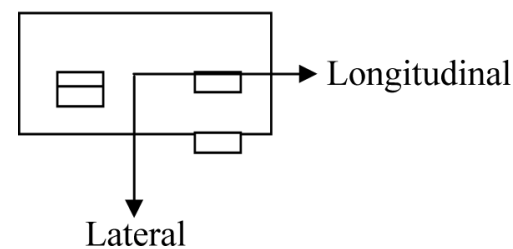

REAR VIEW

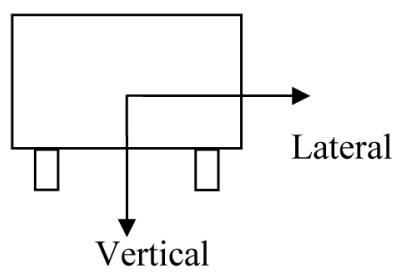

Figure 1.1 Two dimensional representations of vehicle movements.

static load due to weight, and a fluctuating component known as the dynamic tyre force or dynamic wheel load. The static load depends on the geometry and mass distribution of the vehicle and the load sharing characteristics of the suspension system. Uneven load sharing can result in unnecessarily high average tyre a force which leads to high stresses and strains in the contact surface. Dynamic tyre forces are caused when the vehicle moves on the uneven road surface.

The dynamic tyre forces generate additional dynamic stresses. The tyre contact forces play an important role particularly in crash avoidance situations, where the driver is attempting to avoid accidents with near limit performance maneuvering. Depending on the nature of maneuvering limit performance conditions, it can be of loss in directional stability and / or rollover.

\section{Car Suspension Forces and Stability}

The suspension plays an important role in vehicle handling through its effect on body roll and dynamic loading on the tyres. The vertical load on the tyre has a primary influence on cornering stiffness, which in turn determines the lateral force that can be generated during cornering. Compliance in the suspension causes the centre of gravity of the body to roll outward in a turn, relative to the axle transferring load to the outside tyres.

Even though the suspensions comes in a variety of shape and sizes their effect on handling performance can be characterized by several key properties like roll centre height, roll stiffness and lateral stiffness. The vehicles involved in on-road roll-overs are generally out of control prior to the roll, and the lateral stability is the primary vehicle parameter governing such occurrences.

Ferri and Haroon [1] has developed an analytical model incorporating a detailed characterization of suspension components and tyres. The characters quantitatively accounts for both suspension and tyre compliance, in reducing geometric stability and operating stability. He has used the analytical model to design a test table to study the roll-over characteristics of an automobile.

\section{Mathematical Modeling and Simulation}

Modeling and simulation plays an important role in the stability analysis since the simulation assumes the behavior of reality in its absence. The simulation can be carried out by using a computer model or a physical model and the simulation results can be used to predict the behavior of the vehicle in reality related with stability, and ride quality [2-21].

Kim et al. [22] others have developed a validation method for vehicle suspension models and a prediction method of vehicle handling characteristics. They have done suspension model validation by comparing the simulation results of the front and rear suspension models with the wheel alignment characteristics like toe, camber, caster, roll steer, compliance, etc. 
They have also developed a total vehicle model for the prediction of the handling maneuvers. Using this model they have analyzed the vehicle handling maneuvers for a wide range of vehicle operating conditions. Lee and Seewoo [23] in his dissertation work have developed a mathematical model with seventeen degrees of freedom for the motions of a rail vehicle system. He has developed two set of software for the simulation. One is used to carry out the stability analysis and the other is used to analyze the dynamic performance of the railway vehicle systems. The description and illustration of the derivations of the equations of motion (linear mathematical models) of dynamic systems of automobile vehicles as shown in figure, for analyzing lateral dynamics. These equations of motion are derived for an individual vehicle.

The equations of motion are derived by using Newton's law. A right hand coordinate axes system as shown in Figure 1.1 is used for deriving these equations. The sign convention is also illustrated in the same Figure 1.1. The coordinates $\mathrm{X}, \mathrm{Y}$ and $\mathrm{Z}$ represent translational motion in longitudinal, lateral and vertical directions respectively, while $\phi, \chi$ and $\psi$ denote roll, pitch and yaw motion of the body respectively. It may be mentioned that the equations of motion corresponding to the coordinates $(\Psi, \Phi, \psi)$ and the coordinates $(\mathrm{X}, \mathrm{Z}, \mathrm{X})$ are zero coupled. So only the equations of motion corresponding to the coordinates $(\boldsymbol{Y}, \Phi, \psi)$ are needed for analyzing lateral dynamics.

Further, it may be stated that the vehicle body has 3 degrees of freedom corresponding to the longitudinal lateral and yaw directions, while each wheel has 2 degrees of freedom corresponding to the lateral and yaw directions. Thus the model comprising of the vehicle body along with 4 wheels would have 11 degrees of freedom [24-46].

\section{Lumped Mass}

A motor vehicle is made up of many components distributed within its exterior envelope. Yet, under many situations all the components move together. For example under braking the whole vehicle slows down as a single unit. Similarly for acceleration, turning the whole vehicle acts as one unit. Thus the vehicle can be represented as one lumped mass located at its Centre of Gravity with appropriate mass and inertia properties.

The mass at the centre of gravity is dynamically equivalent to the vehicle itself for most of the motion analyses. The lumped mass assumption becomes invalid in some cases such as the ride analysis wherein the wheels are also treated as separate masses thus giving rise to sprung masses and unstrung masses.

\section{Coordinate Systems}

Figure 1.2 and Table 1.1 shows the coordinate systems and the associated movements for a vehicle system. For the theoretical analysis of Vehicle Dynamics, the equations of motion must be known and the physical interactions between various subsystems must be written in the form of mathematical equations.

Usually, vehicle modeling can be done in two approaches. If the aim is to produce an exact model, the theoretical physics methods of Lagrange or Euler's methods can be employed. But here, the calculations are carried out for generalized coordinate systems. The other approach is to model the vehicle as simple as possible with less computing time as well as without affecting the accuracy of the model. The second approach is employed here. In the second approach the calculations are performed in different coordinate systems. In these four types of co- ordinate systems are employed.

The four coordinate systems are:

- COG coordinate system, $C O G$

- Wheel coordinate system, $W$

- Undercarriage coordinate system, $U n$

- Fixed Inertial coordinate system In

The Centre of Gravity coordinate system has its origin at the vehicle COG. All movements of the vehicle body are referenced with respect to this coordinate system. The Undercarriage coordinate system has its origin at the road level at the middle of the perpendicular projection of the

Table 1.1 Coordinate system variables

$\begin{array}{ll}x_{c o g}, y_{c o g}, z_{c o g} & \text { Axes of COG coordinate system } \\ x_{U n}, y_{U n}, z_{U n} & \text { Axes of Undercarriage coordinate system } \\ x_{w^{\prime}}, y_{w^{\prime}}, z_{w} & \text { Axes of Wheel coordinate system } \\ x_{I n}, y_{I n}, z_{I n} & \text { Axes of fixed inertial coordinate system } \\ \Psi & \text { Yaw angle(Rotation about } \mathrm{z}_{\text {cog }} \text { ) } \\ X & \text { Pitch angle(Rotation about } \mathrm{y}_{\operatorname{cog}} \text { ) } \\ \varphi & \text { Roll angle(Rotation about } \mathrm{x}_{\mathrm{cog}} \text { ) } \\ \delta_{w} & \text { Wheel turn angle } \\ \beta & \text { Vehicle body side slip angle }\end{array}$




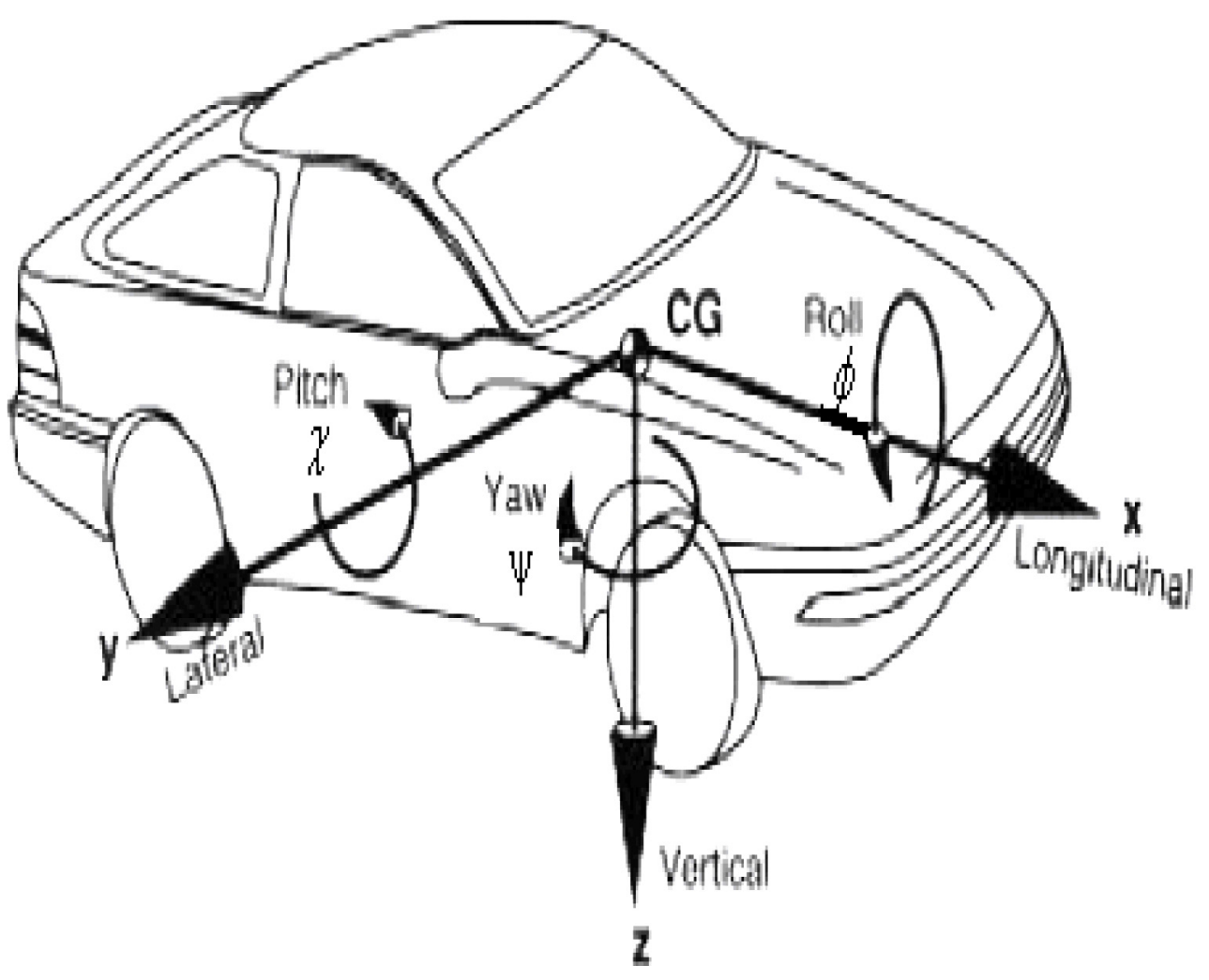

Figure 1.2 Coordinate systems and movements.

rear axle. The Undercarriage coordinate system differs from COG coordinate system only in the Roll and Pitch angles.

The Wheel coordinate system has its origin at the projection of centre of the wheel on the road. Each wheel has its own coordinate system. A vehicle has four Wheel coordinate systems. The fixed inertial coordinate system coincides with the Vehicle coordinate system at the start of maneuver of the vehicle. It does not move with the vehicle wherein the COG coordinate system moves with the vehicle.

\section{Calculation of Tyre Road Contact Point Velocities}

The Vehicle COG velocity is to be transformed to the tyre road contact point to get the tyre road contact point velocity. In addition this shifted velocity component an additional component accounting for the rotational motion of the vehicle around the vertical vehicle axis (Yawing motion) is to be introduced.

The tyre road contact point is at a distance $\boldsymbol{r}_{i j}$ from the vehicle COG. If the rotational velocity (yaw velocity) about the vehicle vertical axis is $\dot{\psi}$ the rotational component is given by the product of the yaw velocity and the distance between the vehicle COG and the tyre road contact point $\left(\boldsymbol{r}_{i j}\right)$. The Figure 1.3 shows the various velocity components of the vehicle.

Thus each tyre velocity has two components

- Component due to Vehicle COG velocity

- Component due to vehicle rotation about vertical axis $(\psi)$

Each of the component is further resolved in the direction of $\boldsymbol{X}_{\operatorname{cog}}, \boldsymbol{Y}_{\operatorname{cog}}$. Thus the tyre road contact point velocities for the tyres are

\section{Front right wheel velocity}

$$
\begin{aligned}
v_{w f r}= & \left(v_{c o g} \cos \beta+\dot{\psi} r_{f r} \cos \gamma_{f r}\right) \vec{e}_{x} \\
& +\left(v_{c o g} \sin \beta+\dot{\psi} r_{f r} \sin \gamma_{f r}\right) \vec{e}_{y}
\end{aligned}
$$

Front left wheel velocity

$$
\begin{aligned}
v_{w f l}= & \left(v_{\operatorname{cog}} \cos \beta-\dot{\psi} r_{f l} \sin \gamma_{f l}\right) \vec{e}_{x} \\
& +\left(v_{\operatorname{cog}} \sin \beta+\dot{\psi} r_{f l} \cos \gamma_{f l}\right) \vec{e}_{y}
\end{aligned}
$$




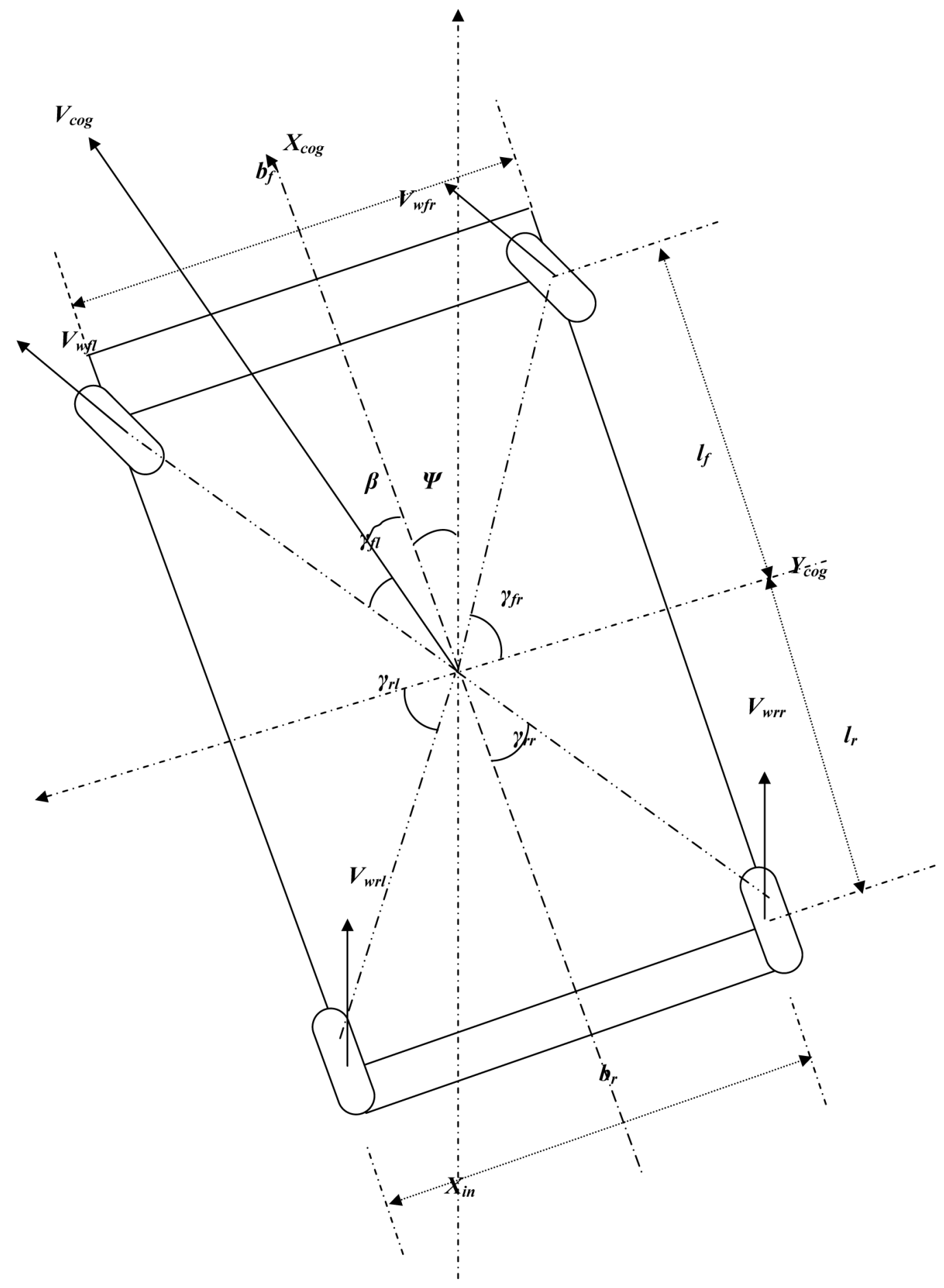

Figure 1.3 Velocity components of a vehicle.

\section{Rear right wheel velocity}

$$
\begin{aligned}
v_{w r r}= & \left(v_{c o g} \cos \beta+\dot{\psi} r_{r r} \sin \gamma_{r r}\right) \vec{e}_{x} \\
& +\left(v_{c o g} \sin \beta-\dot{\psi} r_{r r} \cos \gamma_{r r}\right) \vec{e}_{y}
\end{aligned}
$$

\section{Rear left wheel velocity}

$$
\begin{aligned}
v_{w r l}= & \left(v_{c o g} \cos \beta-\dot{\psi} r_{r l} \cos \gamma_{r l}\right) \vec{e}_{x} \\
& +\left(v_{c o g} \sin \beta-\dot{\psi} r_{r l} \sin \gamma_{r l}\right) \vec{e}_{y}
\end{aligned}
$$


where $\quad \beta$ is the vehicle body side slip angle

$e_{x}$ denotes the longitudinal COG coordinate direction

$e_{y}$ denotes the lateral COG coordinate direction

Figure 1.4 gives the variation of critical speed against wheel base varying from $2.2 \mathrm{~m}$ to $2.9 \mathrm{~m}$. Increase in the wheel base improves the critical speed. But the dimensions of the wheel base depend upon the design constraints and it cannot be increased beyond a certain limit.

Figure 1.5 shows the effect of wheel track on critical speed. It is found that all the four vehicles have a positive response towards critical speed with an increase in the wheel track. Table 1.2 lists the variation in critical speed with respect to Wheel track for the four different types of vehicles.

\section{Conclusion}

A Mathematical model has been developed for the different vehicle movements in the lateral directions. A computer program in ' $\mathrm{C}$ ' language has been developed for the stability analysis. By using the ' $\mathrm{C}$ ' program the critical speed for

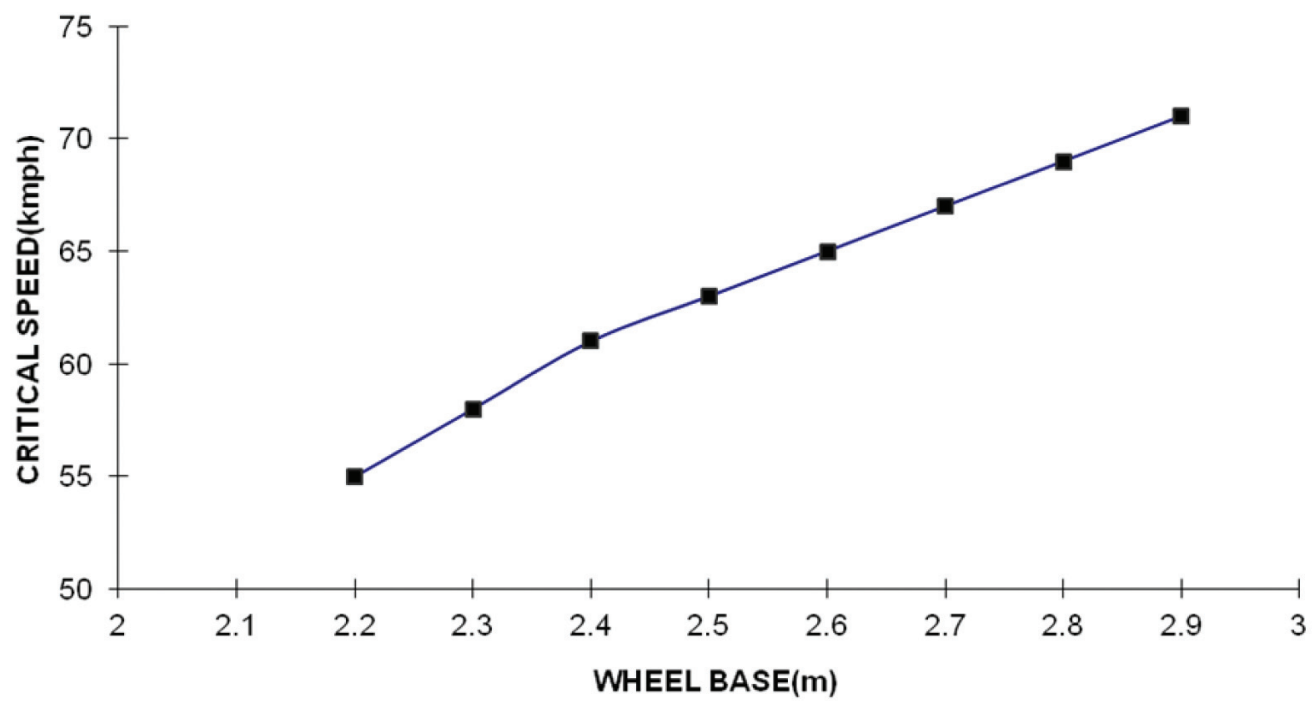

Figure 1.4 Ettect of wheel base on stability.

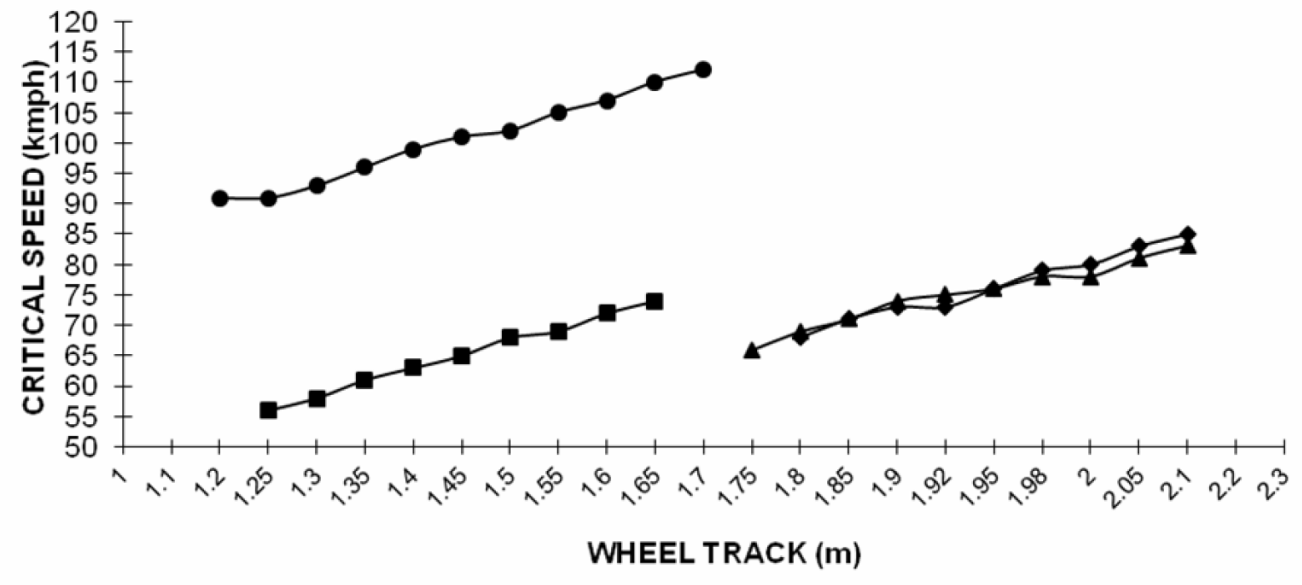

LCV $\multimap$ PASSENGER CAR $\multimap$ BUS TYPE $1 \multimap$ BUS TYPE 4

Figure 1.5 Shows the effect of wheel track on critical speed. 
Table 1.2 Effect of wheel base on stability

\begin{tabular}{|c|c|c|c|c|c|c|c|}
\hline \multicolumn{2}{|c|}{$\mathrm{LCV}$} & \multicolumn{2}{|c|}{ Passenger Car } & \multicolumn{2}{|c|}{ Bus Type - I } & \multicolumn{2}{|c|}{ Bus Type - II } \\
\hline Wheel base (m) & $\begin{array}{l}\text { Critical speed } \\
(\mathrm{kmph})\end{array}$ & Wheel base (m) & $\begin{array}{l}\text { Critical speed } \\
(\mathrm{kmph})\end{array}$ & Wheel base (m) & $\begin{array}{c}\text { Critical speed } \\
(\mathrm{kmph})\end{array}$ & Wheel base (m) & $\begin{array}{c}\text { Critical speed } \\
(\mathrm{kmph})\end{array}$ \\
\hline 2.2 & 55 & 2.2 & 81 & 4.6 & 68 & 5.4 & 71 \\
\hline 2.3 & 58 & 2.3 & 85 & 4.8 & 71 & 5.5 & 74 \\
\hline 2.4 & 61 & 2.4 & 89 & 5.0 & 73 & 5.6 & 76 \\
\hline 2.52 & 63 & 2.5 & 93 & 5.2 & 75 & 5.64 & 79 \\
\hline 2.6 & 65 & 2.67 & 101 & 5.4 & 75 & 5.7 & 82 \\
\hline 2.7 & 67 & 2.7 & 103 & 5.5 & 77 & 5.8 & 84 \\
\hline 2.8 & 69 & 2.8 & 107 & 5.6 & 79 & 5.9 & 85 \\
\hline 2.9 & 71 & 2.9 & 112 & 5.7 & 82 & 6.0 & 88 \\
\hline 3.0 & 72 & 3.0 & 117 & 5.8 & 83 & 6.1 & 89 \\
\hline
\end{tabular}

the different types of vehicles have been found out taking into account of the sensitive and other influencing vehicle parameters. By making a proper choice of the sensitive parameters like the wheel base, wheel track, position of centre of gravity, lateral stiffness, vertical damping and wheel radius the stability of the different types of vehicle systems can be improved. The computer program developed can be used to study the lateral stability of any new vehicle system being developed. The mathematical and the computer model developed are relevant to an automotive vehicle system and this is the first type of work carried out in India to analyze the lateral stability of an automotive vehicle system.

\section{References}

1. Ferri A A, Haroon M et al. (2004). A time and frequency domain approach for identifying non - linear automotive suspension system model in the absence of an Input Measurement, ASEM International Mechanical Engineering Congress and Exposition, IMECE 2004-60211.

2. Allen R W, and Rosenthal T J (1994). Requirements for vehicle dynamics simulation models, SAE paper No. 940175 , Society of Automotive Engineers, Warren dale, PA.

3. Bart E, Hathway C R B et al. (1995). Critical suspension relationship and their influence on transient behavior of vehicles, Society of Automotive Engineers, 1880-1898.

4. Bastow, and Donald (1990). Car Suspension and Handling, London, England: Pentech Press Limited.

5. Cebon D (1987). Assessment of the dynamic wheel forces generated by heavy road vehicles, ARRB/FORS Symposium on Heavy Vehicle Suspension Characteristics, Canberra, Australian Road Research Board.
6. Choromanski W (1988). Simulation researches of mathematical models of nonconventional railway bogies, Engineering Software, New Delhi, India, 435-441.

7. Woods D E, and Jawad B A (1999). Numerical Design of Racecar Suspension Parameter, SAE Journal No. - 1999-012257.

8. Dhar S D, Hohnstadt W E et al. (2002). Integrated modular methodology - philosophy and strategy to build full vehicle finite element model, GM Technical Report, 1-67.

9. Dukkipati R V, and Amyot J R (1988). Computer aided simulation in railway dynamics, Marcel Deckker Inc. New York.

10. Ono E, Asano K et al. (2003). Estimation of automotive tire force characteristics using wheel velocity, Control Engineering Practice, 1361-1370

11. Fancher P S, and Bareket Z (1993). Including roadway and tread factors in semi-empirical model of truck tyres, Supplement to Vehicle System Dynamics, vol 21, 92-107.

12. Cheli F, Pedrinelli $M$ et al. (2006). Integrated modelling of vehicle and driveline dynamics, Proceedings of ESDA 2006 8th Biennial ASME Conference on Engineering Systems Design and Analysis, Torino, Italy.

13. Fukushima N, Hidaka K et al. (1983). Optimum characteristics of automotive shock absorbers under various driving conditions and road Surfaces, International Journal of Vehicle Design, vol 4, No. 5, 463-472.

14. Gerard J, Gouw S R et al. (1990). Increased comfort and safety of drivers of off-highway vehicles using optimal seat suspension, Society of Automotive Engineers, Inc., 701-714.

15. Gillespie T D et al. (1982). Constant Velocity Yaw/Roll Program, The university of Michigan Transportation Research Institute, IMTRI, 82-39.

16. Wallentowitz H, Kohn P et al. (1999). Dynamic properties of tyres - testing and simulation, Society of Automotive Engineers, Inc, 1548-1553. 
17. Heydinger G J et al (1990). Validation of vehicle stability and control simulations, SAE Paper 900128, Society of Automotive Engineers, Warrendale, PA.

18. Iacovoni D H (1969). Fundamentals of automobile handling analysis, warrendale, PA: Society of Automotive Engineers, Inc.

19. Svendenius J, and Wittenmark B (2003). Brush tire model with increased flexibility, European Control Conference.

20. Lee J, Thompson D J et al. (2000). Vibration analysis of a vehicle body and suspension system using a substructure synthesis method, International Journal of Vehicle Design, vol 24, 360-371.

21. Kiencke U, and Nielsen L (2000). Automotive Control Systems, for Engine, Driveline and Vehicle, Springer.

22. Kim M G, Kim J H et al. (1991). Vehicle suspension model validation and dynamic simulatiom, SAE paper

23. Lee and Seewoo (1994). Development of new dynamic tire model for improved vehicle dynamics simulation, Ph.D. Dissertation, The Ohio State University.

24. Li L, Sandu C et al. (2005). Modeling and simulation of a full vehicle with parametric and external uncertainties, ASME International Mechanical Engineering Congress and Exposition, Orlando, Florida USA.

25. Loeb J S et al. (1990). Lateral Stiffness, cornering Stiffness and Relaxation length of the Pneumatic Tire, SAE Paper 900129, Society of Automotive Engineers, Warren dale, P.A.

26. Dohi M, and Maruyama Y (1990). Ride Comfort Optimization for Commercial Trucks, Isuzu Motors Ltd., 890-908.

27. D’Alfio N, Morgando A et al. (2005). Base Model Simulator (BMS) - A vehicle dynamics model to evaluate chassis control systems performance, SAE 2005-01-0401.

28. Oralandea N et al. (1977). Simulation of a vehicle suspension with the Adams computer program, SAE Paper No. 770053.

29. Flores-Centeno O, Fabela-Gallegos M J et al. (2004). Effect of wheelbase variation on the dynamic behavior of a three axles, Heavy Duty Truck, SAE International 120-124.

30. Pacejka H B (1980). Tyre factors and front wheel vibration, International Journal of Vehicle Design, vol 1, No. 2, 97-119.

31. Peng-Xi'an X, and Xie-Xi'an Y(1999). A tire traction modeling for use in ice mobile, SAE Journal Number: 1999-01-0478.

32. Renner T E, and Barber A J (2000). Accurate tire models for vehicle handling uses the Empirical Dynamics Method, by MTS systems Corp., presented at 2000 International ADAMS Users Conference.
33. Sakai H (1981). Theoretical and experimental studies on the dynamic properties of tyres, International Journal of Vehicle Design, vol 3, No. 3, 333-375.

34. Samuel K, and Clark U S (1971). Mechanics of pneumatic tires, Department of Transportation, U.S. Government Printing Office.

35. Kimbrough S S (1999). Rule-based wheel slip assignment for vehicle stability enhancement, SAE Journal No: 1999-010476.

36. Taylor and Francis (2000), Simulation tools, modeling and identification, for an automotive shock absorber in the context of vehicle dynamic, Vehicle System Dynamics, vol 33, No. 4, 261-285.

37. Umeno T (1998). Observer based estimation of parameter variations and its application to tire pressure diagnosis, Proceedings of IFAC Workshop Advanced in Automotive Control, 23-28.

38. Von Glasner, Ec Povel et al. (1994). Introduction to vehicle/ road and vehicle/bridge interaction, Engineering Foundation Conf. Noordwijkerhout NL.

39. Allen R W and Rosenthal T J (1993). A computer simulation analysis of safety critical maneuvers for assessing round vehicle dynamic stability, Systems Technology, Inc., 1150-1168.

40. Allen R W, Magdaleno R E et al. (1995). Systems Technology, Inc., 484-504.

41. Kang X, and Deng W (2007). Vehicle-trailer handling dynamics and stability control - an Engineering Review, SAE 2007-01-0822.

42. Hou Y, Sun Y et al. (2003). An empirical tire model for non-steady-state side slip properties, SAE Journal No- 200301-3414.

43. Fukada Y (1999). Slip-angle estimation for vehicle stability control, Vehicle System Dynamics, vol 32, 375-388.

44. Yoshimura T, and Emoto Y (2003). Steering and suspension system of a full car model using fuzzy reasoning based on single input rule modules, International Journal of Vehicle Autonomous Systems, vol 1, 237-255.

45. Zhang Y, Palmer T J et al. (1998). Vehicle chassis/suspension dynamics analysis - finite element model versus rigid body mode, SAE Journal No. - 980900.

46. Zardecki D (1998). Mathematical model of car steering system dynamics with regard to gear backlash and friction, Proceedings of VI International Conference Autoprogres'98, 43-52. 